\title{
The cyclin-dependent kinase pathway involving CDK1 is a potential therapeutic target for cholangiocarcinoma
}

\author{
MINAKO YAMAMURA, YASUNORI SATO, KENTA TAKAHASHI, MOTOKO SASAKI and KENICHI HARADA \\ Department of Human Pathology, Kanazawa University Graduate School of Medicine, Kanazawa 920-8640, Japan
}

Received March 29, 2019; Accepted October 10, 2019

DOI: $10.3892 /$ or.2019.7405

\begin{abstract}
Cholangiocarcinoma is an aggressive malignancy with high mortality, and effective therapeutic agents for this cancer are limited. Cyclin-dependent kinase (CDK) pathways are therapeutic targets for various types of cancers; however, their involvement in cholangiocarcinoma remains unclear. The present study examined the biological significance of CDK pathways in cholangiocarcinoma. An immunohistochemical analysis of cholangiocarcinoma tissue sections revealed the upregulated expression of phosphorylated cyclin-dependent kinase 1 (p-CDK1), p-CDK2, cyclin B1, and cyclin E1 in carcinoma cells. The nuclear expression of $\mathrm{p}-\mathrm{CDK} 1$ and cyclin B1 was positively correlated with the presence of lymph node metastasis and the clinical stage, and p-CDK1 expression was also associated with poor patient survival. The treatment of human cholangiocarcinoma cell lines (CCKS-1, TFK-1 and HUCCT-1) with the multi-CDK inhibitor roscovitine decreased p-CDK1 expression, inhibited cell proliferation, arrested the cell cycle at the G1 or G2/M phase, and significantly inhibited carcinoma cell invasion. In vivo studies using a murine xenograft model revealed that an intraperitoneal injection of roscovitine significantly inhibited cholangiocarcinoma cell growth. Roscovitine induced apoptosis in cholangiocarcinoma cells in vitro and in vivo. These results demonstrated the potential of the CDK pathway involving CDK1 as a therapeutic target for cholangiocarcinoma. Furthermore, the immunohistochemical expression of p-CDK1 may be a useful prognostic marker of cholangiocarcinoma.
\end{abstract}

Correspondence to: Dr Kenichi Harada, Department of Human Pathology, Kanazawa University Graduate School of Medicine, 13-1 Takara-machi, Kanazawa 920-8640, Japan

E-mail: kenichih@med.kanazawa-u.ac.jp

Abbreviations: CDK, cyclin-dependent kinase; DAB, 3,3'-diaminobenzidine tetrahydrochloride; ELISA, enzyme-linked immunosorbent assay; p-CDK, phosphorylated CDK; PDAC, pancreatic ductal adenocarcinoma; SD, standard deviation; TUNEL, terminal dUTP nick-end labeling

Key words: cholangiocarcinoma, cyclin-dependent kinase, cell cycle, chemotherapy, prognosis

\section{Introduction}

Cholangiocarcinoma is an aggressive malignancy, and the difficulties associated with its diagnosis at the operative stage and high recurrence rate after surgery result in high mortality $(1,2)$. Cholangiocarcinoma may be resistant to conventional chemotherapeutic agents, and non-surgical therapeutic regimens result in minimally improved patient survival (3). Therefore, the discovery of new therapeutic targets is required to increase favorable outcomes among cholangiocarcinoma patients.

Cyclin-dependent kinases (CDKs) belong to a family of protein kinases that play critical roles in the regulation of the cell cycle machinery, and consist of 21 hypotypes (4). CDK activation is required for cell cycle progression, and is positively regulated by cyclins and negatively regulated by CDK inhibitors. CDK1-cyclin B was revealed to be important for the progression of $\mathrm{G} 2 / \mathrm{M}$, and $\mathrm{CDK} 2$-cyclin E promoted cell cycle transition from the $\mathrm{G} 1$ to $\mathrm{S}$ phase. Furthermore, CDK5 has been revealed to be associated with the regulation of cell migration and invasion (4).

The cell cycle is dysregulated during the carcinogenic process, which is accompanied by the overexpression of positive cell cycle regulators (CDKs and cyclins) and the loss of function of CDK inhibitors (5-7). Dysregulated CDKs have been linked to cancer initiation and progression, and the up-regulated expression of CDKs is closely associated with the poor prognosis of patients with various types of cancers (8-12). Thus, the targeting of CDK pathways represents an effective therapeutic strategy against cancer, and there are several ongoing clinical trials using CDK inhibitors (13).

In pancreatic ductal adenocarcinoma (PDAC), the pharmacological inhibition of CDKs was revealed to be effective in experimental studies, and several CDK inhibitors are currently being examined in clinical trials (13-15). A recent study reported that CDK1 is a synthetic lethal target for KRAS mutant tumors including PDAC (16). Since activating KRAS mutations have been reported in cholangiocarcinoma (17-19), and PDAC shares many biological properties with cholangiocarcinoma, the inhibition of CDKs may be beneficial for the treatment of cholangiocarcinoma.

Several experimental studies on cholangiocarcinoma have examined alterations in the expression of CDKs and cell cycle progression following treatments with anticancer agents other than CDK inhibitors (20-23). However, evidence to directly support the involvement and biological significance of the CDK 
pathways in cholangiocarcinoma is limited. Therefore, we herein examined CDK pathways in cholangiocarcinoma, with the aim of developing a novel therapeutic approach for the disease.

\section{Materials and methods}

Ethical statement. Experiments using human materials were performed with the approval of the Ethics Committee of Kanazawa University Graduate School of Medicine (Permit no. 1985-3). Protocols for animal studies were approved by the Committee of the Institute for Experimental Animals, Kanazawa University Advanced Science Research Center (Permit no. AP-173905).

Cell culture. The human cholangiocarcinoma cell lines, CCKS-1, TFK-1 and HUCCT-1, were used. CCKS-1 was established in our laboratory from abdominal metastasis of cholangiocarcinoma (moderately differentiated adenocarcinoma) (24). TFK1 and HUCCT-1 were provided by Cell Resource Center for Biochemical Research, Tohoku University, Sendai, Japan. CCKS-1 was grown in Dulbecco's modified Eagle's medium/F-12 (Gibco; Thermo Fisher Scientific, Inc.), and TFK-1 and HUCCT-1 were grown in RPMI-1640 medium (Gibco; Thermo Fisher Scientific, Inc.) with $10 \%$ fetal bovine serum and $1 \%$ antibiotic-antimycotic solution (Gibco; Thermo Fisher Scientific, Inc.) at $37^{\circ} \mathrm{C}$ in an atmosphere of $5 \% \mathrm{CO}_{2}$. To block CDK signaling, the multi-CDK inhibitor roscovitine (Cell Signaling Technology, Inc.) was used.

Cell proliferation assay. Cell proliferative activity was examined using the WST-1 assay (Roche Diagnostics GmbH) according to the manufacturer's instructions. Cells were seeded on a 96-well plate at a density of $\sim 2 \times 10^{3}-1 \times 10^{4}$ cells/well. Cells were treated with roscovitine at the concentrations of 2,10 and $20 \mu \mathrm{M}$. After 24, 48 and $72 \mathrm{~h}$ following the treatment, the WST-1 reagent was added and incubated for $1 \mathrm{~h}$ before reading the plate. Absorbance at $450 \mathrm{~nm}$ was measured using a microplate reader. Each assay was conducted in eight sets.

Flow cytometry. Cells were treated with $20 \mu \mathrm{M}$ roscovitine for $24 \mathrm{~h}$ and processed for cell cycle analysis using the BrdU Flow Kit (Nippon Becton Dickinson Company, Ltd.) according to the manufacturer's instructions. Samples were analyzed using BD FACSCanto ${ }^{\mathrm{TM}}$ II Flow Cytometry (BD Biosciences). The percentages of cells in the G1, S, and G2/M phases of the cell cycle were assessed using BD FACSDiva ${ }^{\mathrm{TM}}$ Software (BD Biosciences).

Western blotting. Cells were treated with $20 \mu \mathrm{M}$ roscovitine for $72 \mathrm{~h}$, and proteins were extracted using the T-PER Protein Extraction Reagent (Gibco; Thermo Fisher Scientific, Inc.). Protein concentrations were determined using the Bradfold method. Equal amounts of protein $(50 \mu \mathrm{g})$ were loaded in each lane of an SDS-polyacrylamide gel (5-20\%). Proteins were separated by electrophoresis and transferred to a nitrocellulose membrane. After blocking, the membrane was incubated at $4^{\circ} \mathrm{C}$ overnight with primary antibodies against p-CDK1 (Thr161; 1:500 dilution; cat. no. bs-3481R; rabbit polyclonal; Bioss Antibodies, Inc.), CDK1 (1:1,000 dilution; mouse monoclonal; cat. no. ab18; Abcam), and $\beta$-actin (1:1,000 dilution; cat. no. 4967). rabbit monoclonal; Cell Signaling Technology, Inc.). Following an incubation with the secondary antibody conjugated with peroxidase using Histofine Simple Stain MAX PO (Nichirei Corp.; cat. no. 424142) at room temperature for $1 \mathrm{~h}$, the protein was visualized using 3,3'-diaminobenzidine tetrahydrochloride (DAB). Image analysis was performed using the NIH ImageJ software (National Institutes of Health). Each assay was conducted in five sets.

ELISA assay. The protein levels of p-CDK1 (Thr161) and total CDK1 in cholangiocarcinoma cell lines were determined using an enzyme-linked immunosorbent assay (ELISA). The same samples used for the western blotting were analyzed, and the protein levels were determined using a RayBio ${ }^{\circledR}$ Human phospho-CDK1 (Thr161) and Total CDK1 ELISA kit (RayBiotech) according to the manufacturer's instructions. Optical density was measured using a microplate reader at $450 \mathrm{~nm}$, and the ratio of $\mathrm{p}-\mathrm{CDK} 1 / \mathrm{CDK} 1$ was calculated for each sample. Each assay was conducted in six sets.

Apoptosis assay. DNA fragmentation attributable to apoptosis was assessed by the terminal deoxynucleotide transferase-mediated dUTP nick end-labeling (TUNEL) method. Cells were treated with $20 \mu \mathrm{M}$ roscovitine for $72 \mathrm{~h}$ and processed in a paraffin-embedded cell block. After deparaffinization, sections were stained using a commercial kit (in situ Apoptosis Detection kit; Takara Bio, Inc.) according to the manufacturer's instructions. Color development was performed using DAB, and sections were counterstained with hematoxylin. Five high-power fields were randomly selected under a light microscope, and the percentage of apoptotic cells was calculated.

Invasion assay. Carcinoma cell invasion was examined using the Corning ${ }^{\circledR}$ BioCoat $^{\mathrm{TM}}$ Matrigel $^{\circledR}$ Invasion Chamber (Corning, Inc.) according to the manufacturer's instructions. Cells $\left(\sim 2-15 \times 10^{4}\right.$ cells/well) in a $0.5-\mathrm{ml}$ suspension with or without $20 \mu \mathrm{M}$ roscovitine were seeded in each well. Cells were incubated at $37^{\circ} \mathrm{C}$ for $72 \mathrm{~h}$ and then fixed at room temperature for $12 \mathrm{~h}$ with $10 \%$ neutral formalin. Cells were stained with Diff-Quick (Sysmex Corp.) at room temperature for $15 \mathrm{sec}$. Migrated cells were visualized under a light microscope, and the number of cells was counted in five randomly selected high-power fields.

Murine xenograft model. Five-week-old BALB/cAnNCrj$\mathrm{nu} / \mathrm{nu}$ nude mice (male) were obtained from Charles River Laboratories, Inc. CCKS-1 was implanted subcutaneously into the right flanks of mice. On day 20, tumor-bearing mice were randomly divided into two groups (control and treatment groups), and five mice were included in each group. Roscovitine (ChemScene) was administered to mice by an intraperitoneal injection at a dose of $50 \mathrm{mg} / \mathrm{kg}$ for two 5-day series with a 2-day break in between. Control mice were treated with carrier solution alone. Tumor sizes were measured every day, and the tumor volumes were calculated using the following formula: $(1 / 2) \mathrm{LxW}^{2}$, where $\mathrm{L}$ and $\mathrm{W}$ represented the longest tumor axis $(\mathrm{mm})$ and the shortest tumor axis $(\mathrm{mm})$, respectively. The fold difference from the initial tumor volume (measured at day 20) was defined as the tumor growth rate (25). 
On day 33 (13 days after the first injection of roscovitine), the mice were sacrificed by inhalation of $\mathrm{CO}_{2}$ with a $20 \%$ volume/min gas displacement flow rate until euthanasia was confirmed by the arrest of heartbeat and breathing. Formalin-fixed paraffin-embedded sections of dissected tumors were used for the apoptosis assay and the immunostaining of Ki-67.

Immunohistochemistry. Fifty-four cases of extrahepatic cholangiocarcinoma collected from Kanazawa University Hospital and its affiliated hospitals were examined. Sample collection was conducted during the periods from August 1994 to July 2016. All cases surgically resected were diagnosed as conventional cholangiocarcinoma. The median age of the patients was 69 years ranging from 35 to 84 years, and the male:female ratio was 33:21. The tumor-node-metastasis (TNM) classification was used according to the guidelines of the International Union Against Cancer (26). Cholangiocarcinoma cell lines (CCKS-1, TFK-1, and HUCCT-1) and tumor tissues obtained from a murine xenograft model were also used for the immunohistochemical analysis. Samples were fixed at room temperature for $48 \mathrm{~h}$ in $10 \%$ neutral formalin, embedded in paraffin, and 4- $\mu \mathrm{m}$-thick paraffin-embedded sections were prepared.

After deparaffinization, antigen retrieval was performed by microwaving in $10 \mathrm{mmol} / \mathrm{l}$ citrate buffer ( $\mathrm{pH} \mathrm{6.0)} \mathrm{for}$ the immunostaining of p-CDK1, cyclin B1, and cyclin E1. Regarding the immunostaining of Ki-67, antigen retrieval was performed by heating in Tris-ethylenediaminetetraacetic acid buffer ( $\mathrm{pH}$ 9.0) with a pressure cooker. Sections were immersed in $0.3 \%$ hydrogen peroxidase in methanol for $20 \mathrm{~min}$ to block endogenous peroxidase activity and then incubated in protein block solution (Dako; Agilent Technologies, Inc.). Sections were incubated overnight at $4{ }^{\circ} \mathrm{C}$ with primary antibodies against p-CDK1 (Thr161; 1:100 dilution; cat. no. bs-3481R), rabbit polyclonal; Bioss Antibodies, Inc.), cyclin B1 (1:100 dilution; cat. no. ab32053; rabbit; monoclonal; Abcam), cyclin E1 (1:100 dilution; cat. no. ab33911; rabbit monoclonal; Abcam), or Ki-67 (prediluted; cat. no. 418071; rabbit monoclonal; Nichirei Corp.). Sections were then incubated with the secondary antibody conjugated with peroxidase using Histofine Simple Stain MAX PO [Nichirei Corp. (cat. no. 424142)] at room temperature for $1 \mathrm{~h}$. Color development was performed using DAB, and sections were counterstained with hematoxylin.

The immunostaining of $\mathrm{p}$-CDK2 was performed using the Novolink $^{\mathrm{TM}}$ Polymer Detection System (Leica Biosystems) according to the manufacturer's protocol. Briefly, after blocking endogenous peroxidase using Peroxidase Block for $5 \mathrm{~min}$ and a pretreatment with Protein Block for $5 \mathrm{~min}$, sections were incubated at $4^{\circ} \mathrm{C}$ overnight with the primary antibody against p-CDK2 (Thr160; 1:100 dilution; rabbit polyclonal; Abcam cat. no. ab194868). Sections were then treated with Post Primary Block followed by Novolink Polymer at room temperature for $30 \mathrm{~min}$. Immunoreactivity was visualized using DAB Working Solution, and sections were counterstained with hematoxylin.

Histological evaluation. A semiquantitative analysis of the immunohistochemical staining of p-CDK1, p-CDK2, cyclin B1, and cyclin E1 was performed for surgically resected specimens. Staining in the nuclei or cytoplasm of cholangiocarcinoma cells was individually evaluated, and staining in each section was graded as follows: (-), negative or $<5 \%$ of carcinoma cells were positive; $(+),>5 \%$ of carcinoma cells were positive.

The expression of Ki-67 was assessed by counting at least 1,000 cholangiocarcinoma cells in an area with the greatest staining density that was selected in an x200 magnification field under a light microscope. The percentage of cells that were positive for Ki-67 was expressed as the Ki-67-labeling index.

Statistical analysis. Data were expressed as the mean \pm standard deviation (SD). The significance of differences was analyzed using the Student's t-test and chi-squared test. In the univariate analysis, postoperative survival probability was calculated by the Kaplan-Meier method, and survival curves were compared by the Log-rank test using BellCurve ${ }^{\circledR}$ for Excel software (Social Survey Research Information Co., Ltd.). A P-value $<0.05$ was considered to indicate a statistically significant difference.

\section{Results}

Upregulation of $C D K$ and cyclin expression in cholangiocarcinoma tissues. The immunohistochemical expression of p-CDK1, p-CDK2, cyclin B1, and cyclin E1 was absent or weak in non-neoplastic biliary epithelial cells. In cholangiocarcinoma, the upregulation of protein expression was observed in a number of cases (Fig. 1). Positive immunohistochemical signals for CDKs and cyclins were observed in both the nuclei and cytoplasm of carcinoma cells, and the extent of positive staining varied from patchy to diffuse. Among the 54 cholangiocarcinoma cases examined, positive nuclear expression for p-CDK1, p-CDK2, cyclin B1, and cyclin E1 was observed in 29 cases (54\%), 18 cases (33\%), 32 cases (59\%), and 34 cases (63\%), respectively (Table I). No correlations were noted between the positivity of p-CDK1 and cyclin B1 or the positivity of p-CDK2 and cyclin E1 (data not shown).

Clinicopathological significance of CDK and cyclin expression in cholangiocarcinoma. The relationship between clinicopathological factors and the immunohistochemical expression of CDKs and cyclins was examined. The nuclear expression of p-CDK1 and cyclin B1 was positively associated with the presence of lymph node metastasis and the clinical stage (Table I). The nuclear expression of p-CDK2 and cyclin E1 was not associated with these clinicopathological factors. The expression of p-CDK1, p-CDK2, cyclin B1, and cyclin E1 in the cytoplasm of carcinoma cells was not associated with any clinicopathological factors (data not shown).

Postoperative follow-up data were analyzed with a median follow-up period of 21.8 months for the overall survival ratio and 18.0 months for the disease-free survival ratio. Patients with the positive nuclear expression of p-CDK1 had a significantly poor prognosis (Fig. 2). In contrast, no correlation was observed between patient prognosis and the nuclear expression of p-CDK2, cyclin B1, and cyclin E1 (Fig. 2). The cytoplasmic expression of p-CDK1, p-CDK2, cyclin B1, and cyclin E1 was not associated with patient prognosis (data not shown).

A group of disease-free surviving individuals was observed within the p-CDK1-positive cohort of patients. 


\section{Cholangiocarcinoma}

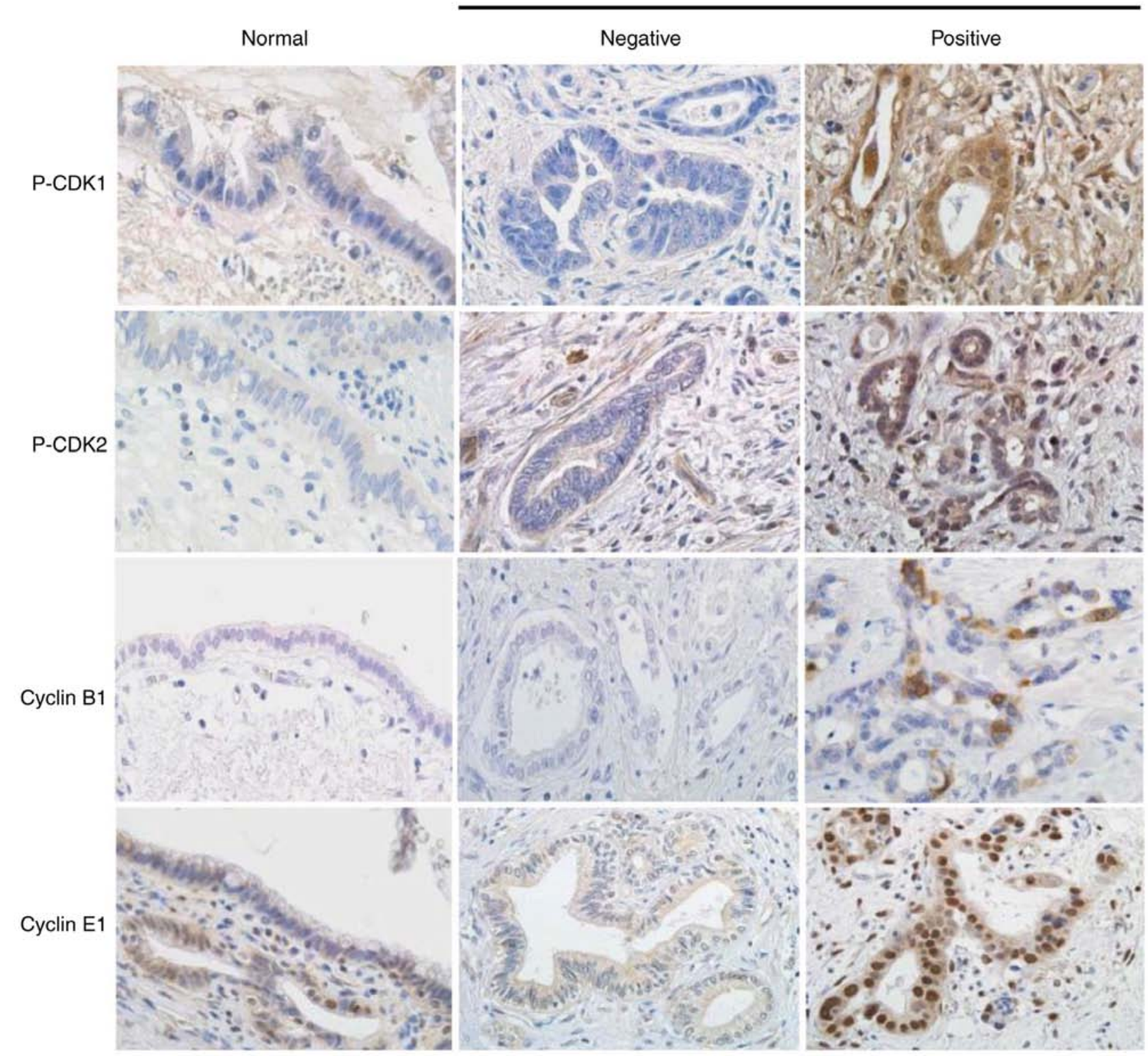

Figure 1. Immunohistochemical expression of CDKs and cyclins in cholangiocarcinoma. The expression of p-CDK1, p-CDK2, cyclin B1, and cyclin E1 was observed in a number of cholangiocarcinoma cases. The expression of these molecules in normal biliary epithelial cells was absent or weak. Original magnification, x400. CDKs, cyclin-dependent kinases; p-CDK1, phosphorylated cyclin-dependent kinase 1.

Disease-free surviving patients were also present in the p-CDK2-, cyclin B1-, and cyclin E1-negative groups. These surviving patients appeared to have cholangiocarcinoma with a well-differentiated histology.

The present results indicated that the activation of the CDK pathway involving CDK1 rather than CDK2 defined the tumor aggressiveness of cholangiocarcinoma. To further clarify their involvement in cholangiocarcinoma, in vitro experiments were performed.

Effects of CDK inhibition on cholangiocarcinoma biology in vitro. The human cholangiocarcinoma cell lines, CCKS-1, TFK-1, and HUCCT-1 were used. Immunostaining revealed that $\mathrm{p}-\mathrm{CDK} 1$ was expressed in the nuclei of all three cell lines, and its expression was stronger in CCKS-1 and HUCCT-1 than in TFK-1 (Fig. 3A). When cells were treated with the
multi-CDK inhibitor roscovitine, cell proliferative activity was inhibited in the three cell lines in time- and dose-dependent manners, with $20 \mu \mathrm{M}$ roscovitine exerting the strongest effects (Fig. 3B). In subsequent in vitro experiments, roscovitine was used at a dose of $20 \mu \mathrm{M}$.

The western blot analysis indicated that the treatment with roscovitine reduced the expression of $\mathrm{p}-\mathrm{CDK} 1$ in the cells (Fig. 3C), and the analysis using ELISA further confirmed that the ratio of p-CDK1/CDK1 was significantly reduced by the treatment (Fig. 3D). Following treatment with roscovitine, the cell cycle was arrested at the G1 or G2/M phase in CCKS-1, TFK-1, and HUCCT-1 (Fig. 4), and this was accompanied by an increase in the percentage of apoptotic cells (Fig. 5A and B). Furthermore, the invasion of cholangiocarcinoma cells was significantly inhibited by the treatment with roscovitine (Fig. 5C and D). 


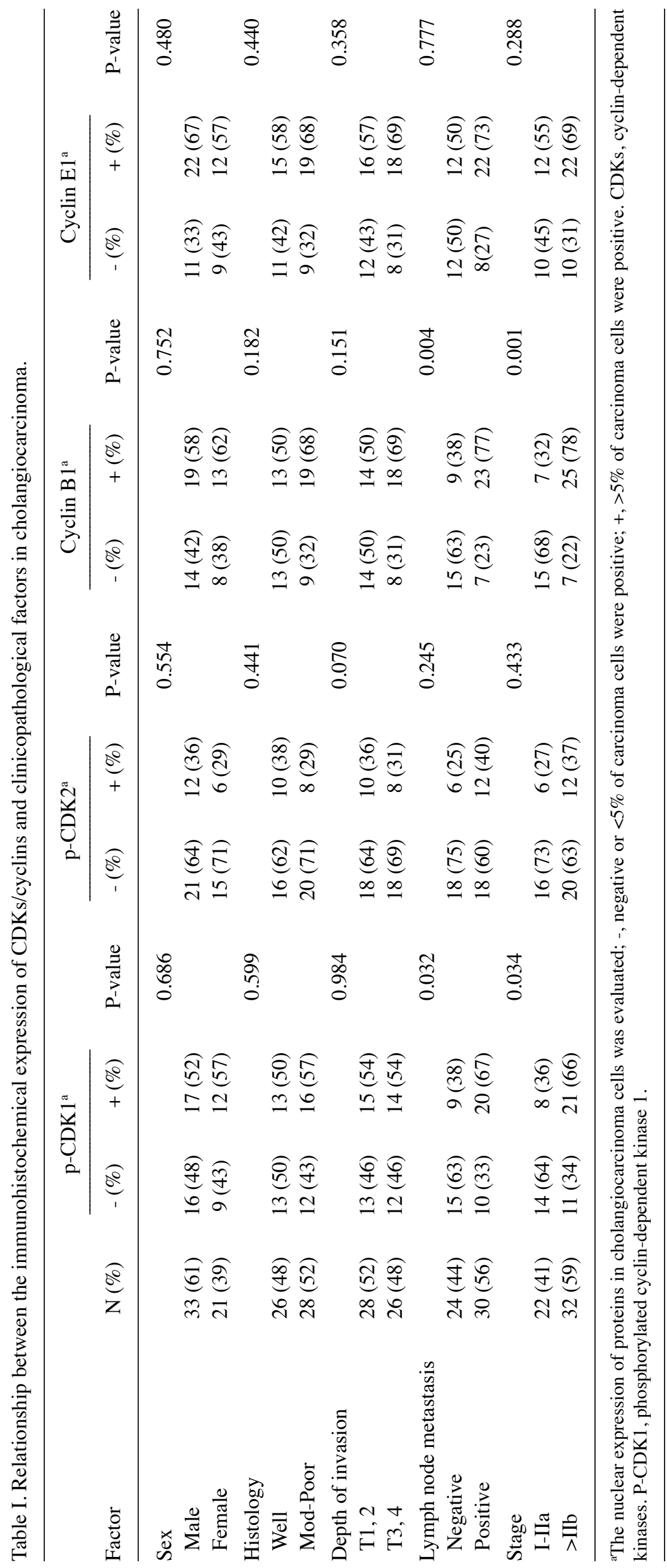


P-CDK1

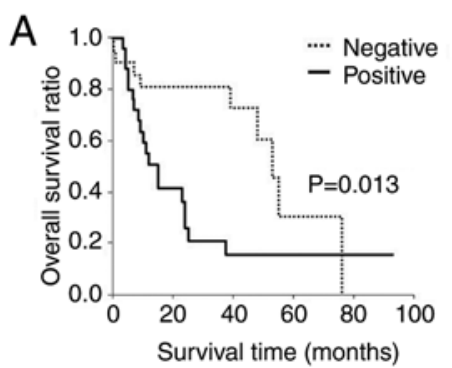

P-CDK1

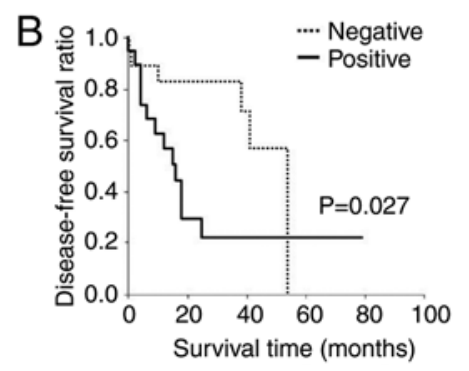

P-CDK2

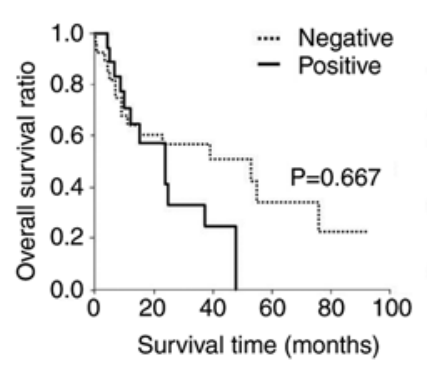

P-CDK2

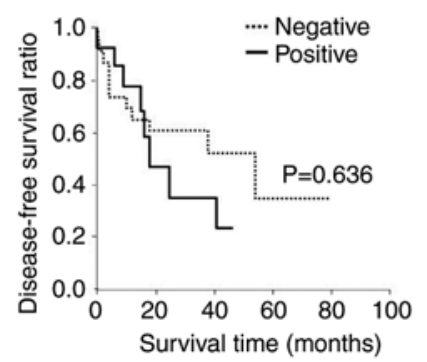

Cyclin B1
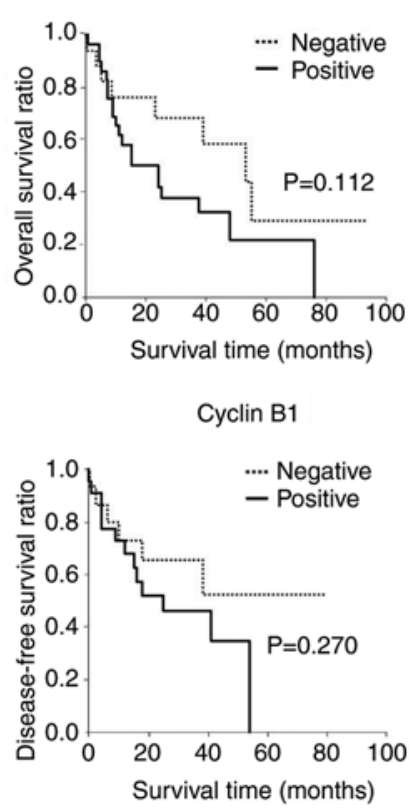

Cyclin E1

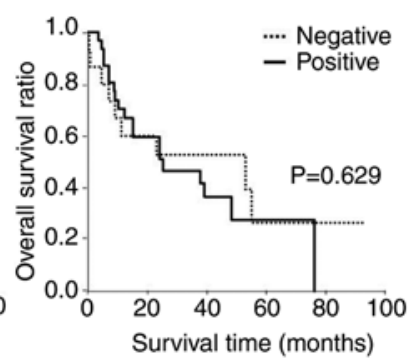

Cyclin E1

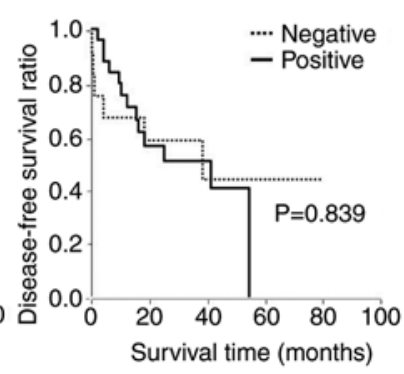

Figure 2. Survival curve of cholangiocarcinoma cases in relation to the immunohistochemical expression of CDKs and cyclins. Patients with positive nuclear expression of p-CDK1 exhibited a significantly worse prognosis in (A) overall survival and (B) disease-free survival. The nuclear expression of p-CDK2, cyclin B1, and cyclin E1 was not associated with patient survival. Survival curves were compared by the log-rank test. CDKs, cyclin-dependent kinases; p-CDK1, phosphorylated cyclin-dependent kinase 1 .

Effects of CDK inhibition on cholangiocarcinoma in a murine xenograft model. The subcutaneous implantation of CCKS-1 was used in the analysis of the murine xenograft model. An intraperitoneal injection of roscovitine inhibited tumor growth in this model, and a significant difference was noted in the tumor growth rate between the untreated and treated groups between 10 and 13 days after roscovitine treatment (Fig. 6A and B). Tumors in the untreated group grew up to a volume of $847 \mathrm{~mm}^{3}$ (6.7-fold growth against the initial size), whereas tumors in the treated group had a maximum volume of $600 \mathrm{~mm}^{3}$ (3.0-fold growth against the initial size).

Similar to the results of the in vitro experiments, the apoptotic response of cholangiocarcinoma cells was significantly induced by the treatment (Fig. 6C and D). The Ki-67-labeling index of cholangiocarcinoma cells was significantly reduced by the treatment (Fig. 6C and E). Thus, roscovitine was an effective agent to treat cholangiocarcinoma in vivo.

\section{Discussion}

The present study revealed the significant involvement of the CDK pathway and CDK1 in cholangiocarcinoma. CDK1 and related molecules play key roles in the cell cycle, and the upregulated expression of CDK1 occurs in a number of human malignant tumors (9-12). CDK1 forms a complex with cyclin B1, and the CDK1-cyclin B1 complex (M-phase promoting factor) is indispensable for cell cycle transition into the $\mathrm{G} 2 / \mathrm{M}$ phase $(27,28)$. The $\mathrm{CDK} 1$ protein is activated by phosphorylation at the Thr161 amino acid activation site and by dephosphorylation at the Thr14/Tyr15 amino acid inhibition sites. CDK1 and cyclin B1 are located in both the nuclei and cytoplasm of cells, and the activation of CDK1-cyclin B1 triggers its rapid accumulation in nuclei $(28,29)$.
The immunohistochemical analysis revealed that the nuclear expression of p-CDK1 (Thr161) and cyclin B1, rather than their cytoplasmic expression, was correlated with clinicopathological factors and/or patient prognosis. These results indicated that the activation of CDK1-cyclin B1 contributes to the aggressive behavior of cholangiocarcinoma. Since the immunohistochemical expression of p-CDK1 and cyclin B1 was absent or weak in normal biliary epithelial cells and hepatocytes, the therapeutic inhibition of the CDK pathway involving CDK1 may have less hepatotoxicity for the normal liver physiology.

Positive correlations have been suggested between CDK phosphorylation and their downstream targets, including cyclins. However, the immunohistochemical analysis revealed no correlations between $\mathrm{p}-\mathrm{CDK} 1 /$ cyclin $\mathrm{B} 1$ and p-CDK2/cyclin E1 positivity. After the mitotic phase, $\mathrm{p}-\mathrm{CDK} 1 /$ cyclin $\mathrm{B} 1$ are inactivated by dephosphorylation and the destruction of cyclin B1 (28). The activation of CDK2 requires the assembly of cyclin $\mathrm{E}$ and phosphorylation at the Thr160 amino acid activation site by CDK activation enzymes. p-CDK2/cyclin E1 are inactivated by dephosphorylation at the Thr14/Tyr15 amino acid inhibition site by cdc25A, and the destruction of cyclin E occurs via ubiquitination and proteasome processing during the $\mathrm{S}$ phase $(30,31)$. Although the exact reason for this currently remains unclear, the complex interactions between CDKs, cyclins, and other related molecules may account for the lack of correlations between p-CDK1/cyclin B1 and $\mathrm{p}-\mathrm{CDK} 2 /$ cyclin E1 positivity.

CDK inhibitors exert antitumor effects in various types of cancers, and CDK1 is a target molecule (13-15,32-34). Roscovitine is a broad-range purine inhibitor that inhibits CDK1, CDK2, CDK5, and CDK 7 through direct competition at the ATP-binding site. Roscovitine inhibits cell proliferation 
A

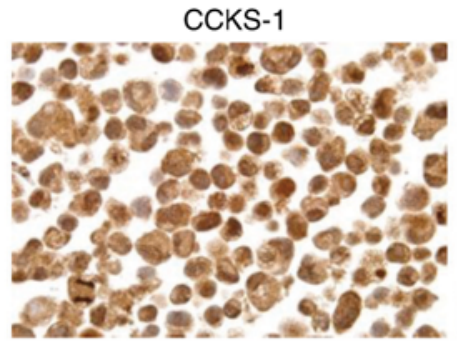

TFK-1

HUCCT-1

B CCKS-1
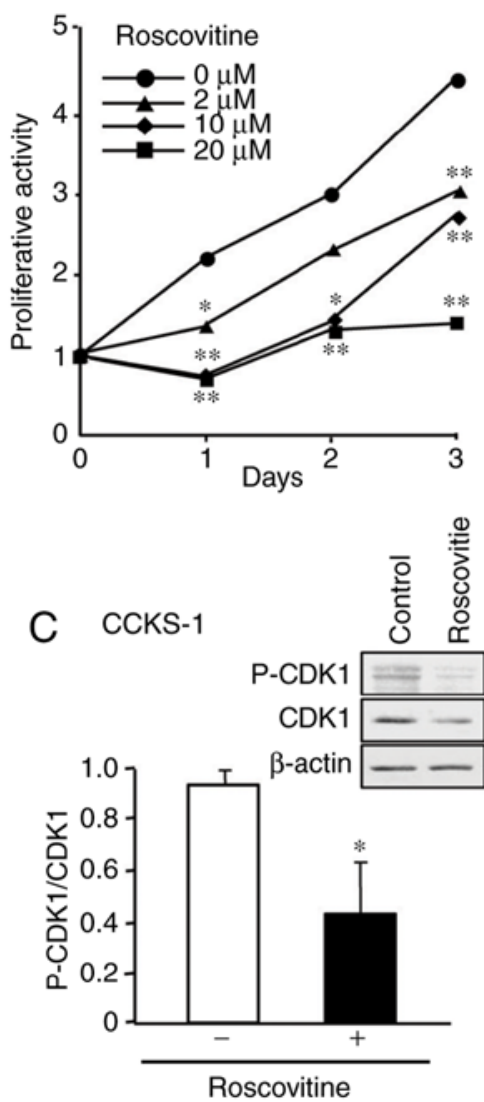

D CCKS-1

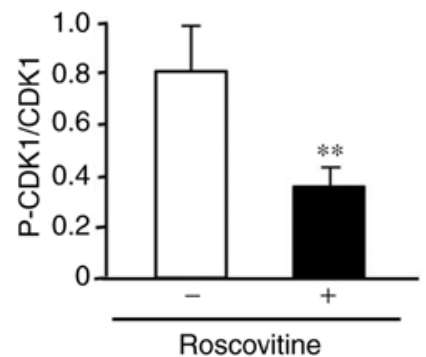

TFK-1
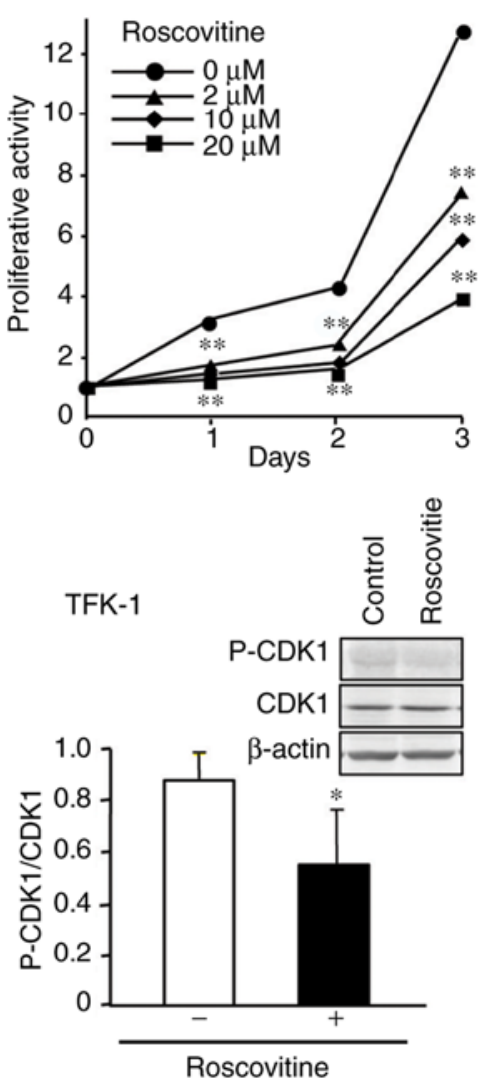

TFK-1

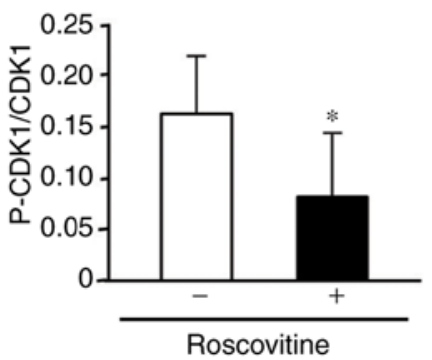

HUCCT-1
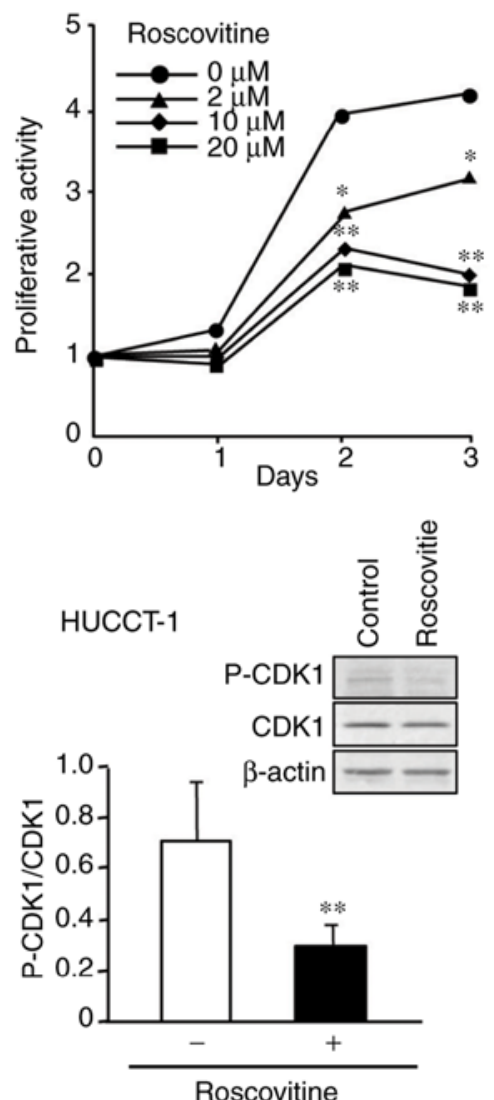

HUCCT-1

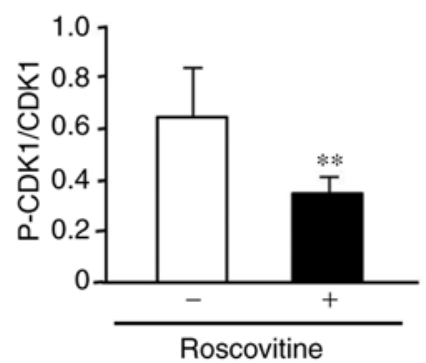

Figure 3. Effects of roscovitine on the cell proliferative activity of cholangiocarcinoma in vitro. (A) Immunohistochemical expression of p-CDK1 in the human cholangiocarcinoma cell lines, CCKS-1, TFK-1, and HUCCT-1. (B) The inhibition of the cell proliferative activity of these cell lines following the treatment with roscovitine that was assessed using the WST-1 assay. (C) A western blot analysis indicating the reduced expression of p-CDK1 following roscovitine treatment. The ratio of $\mathrm{p}-\mathrm{CDK} 1 / \mathrm{CDK} 1$ was determined for each sample. Representative western blots are presented in the upper right corner of each figure, in which the image in each square was captured from the same blotting membrane. (D) An ELISA analysis revealing that roscovitine treatment reduced the ratio of $\mathrm{p}-\mathrm{CDK} 1 / \mathrm{CDK} 1$ in the cells. Data were expressed as the mean $\pm \mathrm{SD}$ of (B) eight, (C) five, and (D) six sets. The significance of differences was assessed using the Student's t-test. ${ }^{*}<<0.05,{ }^{* *} \mathrm{P}<0.01$. Original magnification, $\mathrm{x} 1,000$ (A). p-CDK1, phosphorylated cyclin-dependent kinase 1.

in various cancers, and the anti-proliferative effect is mediated by cell cycle arrest, which is accompanied by the induction of apoptosis (35-38). Regarding the application of roscovitine to biliary diseases, it was revealed to inhibit cholangiocyte growth (liver cystogenesis) in a mouse model of autosomal dominant polycystic kidney disease (39). Consistent with previously reported findings, it was revealed that roscovitine inhibited the cell proliferation of cholangiocarcinoma, decreased the 

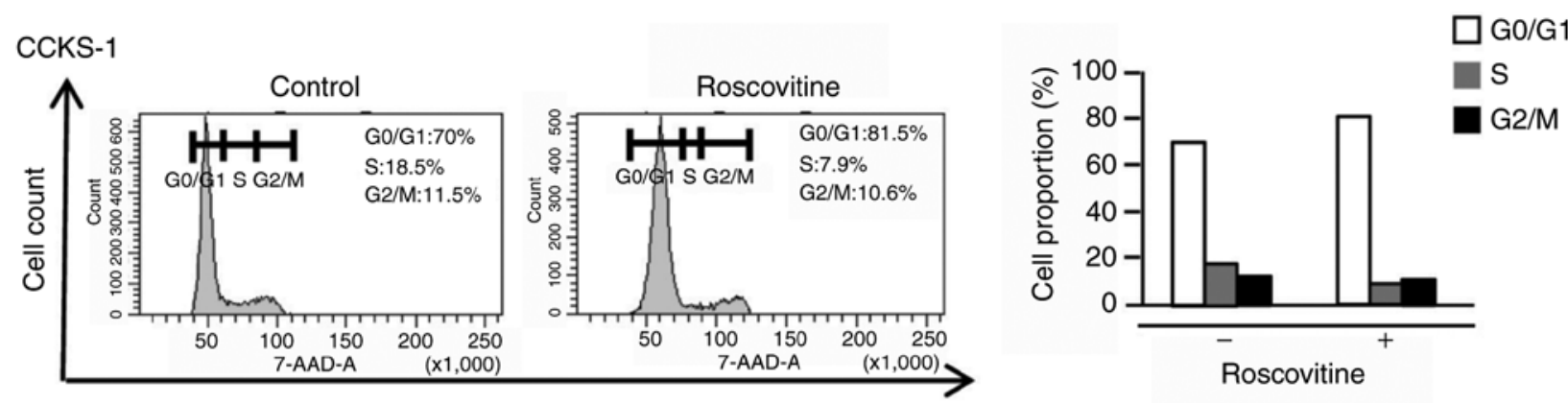

7-ADD

TFK-1
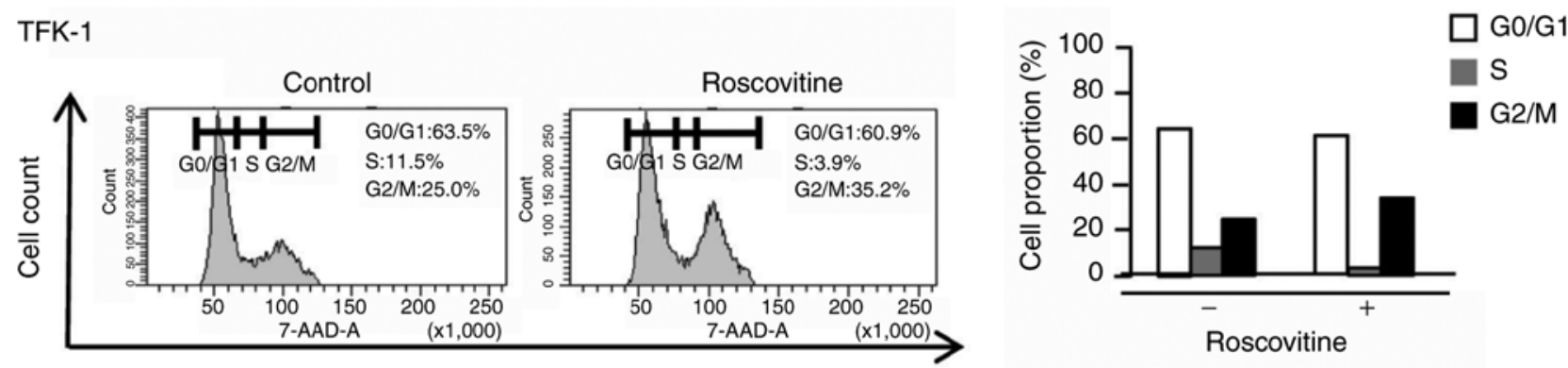

7-ADD

HUCCT-1
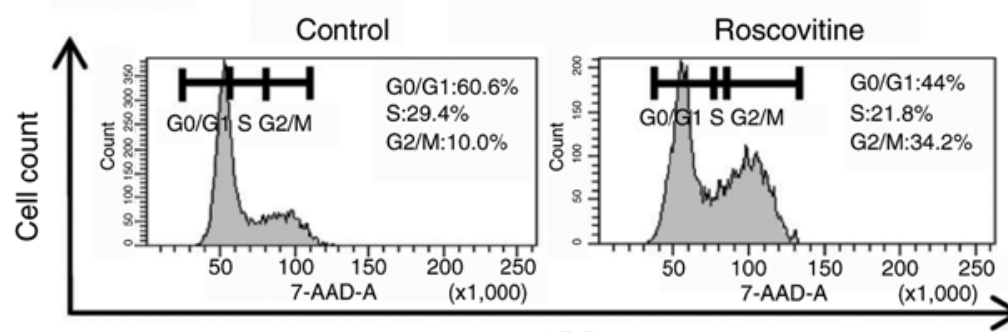

7-ADD

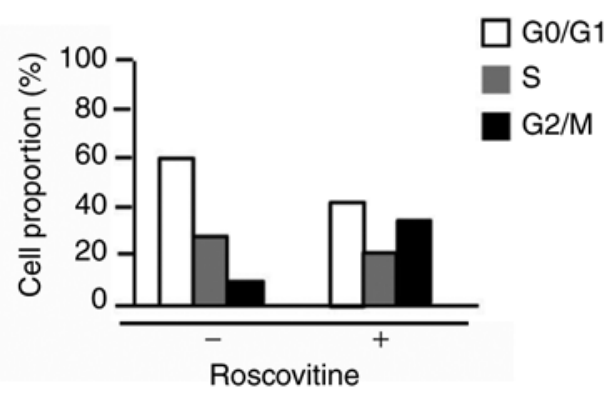

Figure 4. Effects of roscovitine on the cell cycle progression of cholangiocarcinoma in vitro. A flow cytometric analysis using the human cholangiocarcinoma cell lines, CCKS-1, TFK-1, and HUCCT-1. The treatment with roscovitine resulted in cell cycle arrest at the G1 or G2-M phase. Data were expressed as the percentage of total cells. Representative images of three independent experiments are presented.

expression of $\mathrm{p}-\mathrm{CDK} 1$, arrested the cell cycle at the $\mathrm{G} 1$ or G2/M phase, and induced apoptosis. Furthermore, roscovitine inhibited the invasion of cholangiocarcinoma cells in vitro. The activation of CDK5 was revealed to be involved in the invasion of PDAC, and the inhibition of cholangiocarcinoma cell invasion may be associated with the inhibitory effects of roscovitine on CDK5 activation (40).

In vivo studies further confirmed that roscovitine significantly inhibited cell proliferative activity, and induced apoptosis in a murine xenograft model of cholangiocarcinoma. These results were consistent with the data of previous studies that demonstrated the antitumor effects of roscovitine in vivo $(25,37,41)$. It has been reported that roscovitine induced apoptosis in a xenograft model of Ewing's sarcoma family tumor by a caspase-dependent mechanism (25). Another study revealed that roscovitine enhanced the antitumor effects of doxorubicin by inducing $\mathrm{G} 2 / \mathrm{M}$ arrest rather than apoptosis accompanied by the increase of p27 expression in a breast cancer xenograft model (41). Although the detailed mechanism requires study, it is plausible that the xenograft growth inhibition by roscovitine relates to the complex interaction of molecules included in different signaling pathways, and the inhibition of cell cycle progression and the induction of apoptosis may be important factors attributable to the antitumor effects of roscovitine in vivo. The inhibition of tumor invasion may also contribute to the antitumor effects.

KRAS mutant tumor cells have elevated CDK1 activity, and CDK1 may be a synthetic lethal target for KRAS mutant tumors including PDAC (16). Activating KRAS mutations are frequently observed in cholangiocarcinoma predominantly of the perihilar and distal types and are reported to be present in up to $40 \%$ of cases (17-19). CCKS-1 and HUCCT-1 were revealed to harbor a KRAS mutation (G12D), whereas TFK-1 had no mutation at codon 12 of $\operatorname{KRAS}(42,43)$. The stronger nuclear expression of p-CDK1 in CCKS-1 and HUCCT-1 than in TFK-1 may reflect the presence of KRAS mutations in cells, and suggests that CDK1 is a preferable therapeutic target for cholangiocarcinoma with KRAS mutations.

In the present study, the nuclear expression of $\mathrm{p}-\mathrm{CDK} 1$ was also observed in TFK-1. Although p-CDK1 expression in TFK-1 was weak on immunostaining, the presence of p-CDK1 indicates its potential as a therapeutic target. The multi-CDK inhibitor roscovitine inhibited cell proliferative activity and arrested the cell cycle in TFK-1 as well as in CCKS-1 and HUCCT-1; however, the extent of the involvement of CDK1 inhibition in these inhibitory effects was 
A

CCKS-1

TFK-1

HUCCT-1

Control

Roscovitine
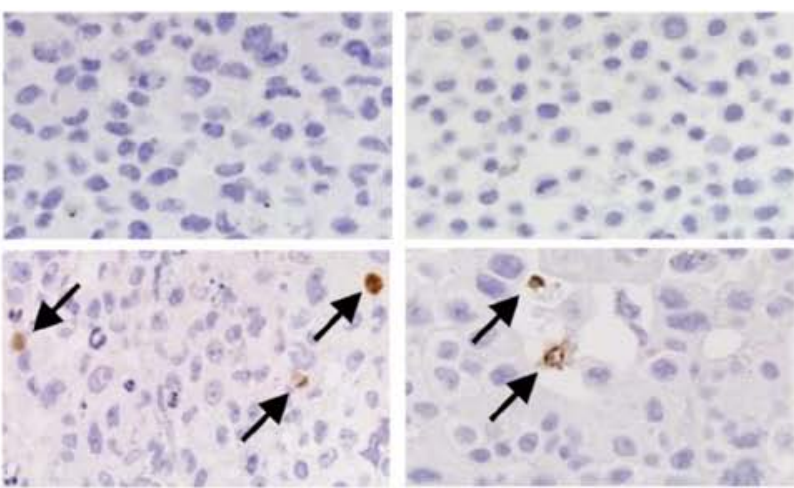

TFK-1

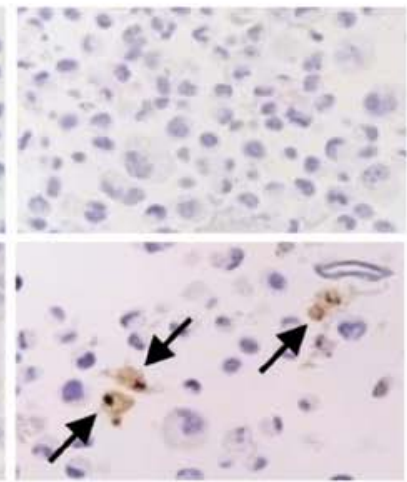

B

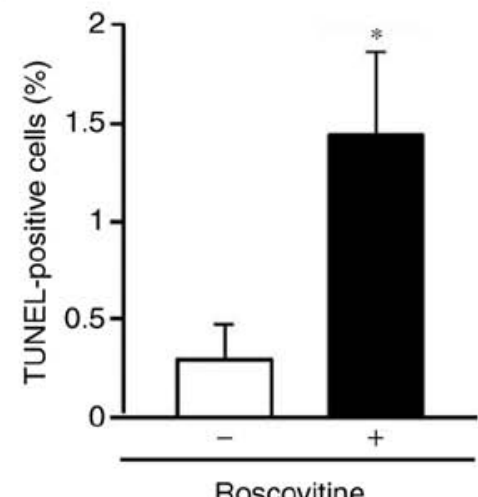

C

Control

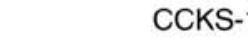

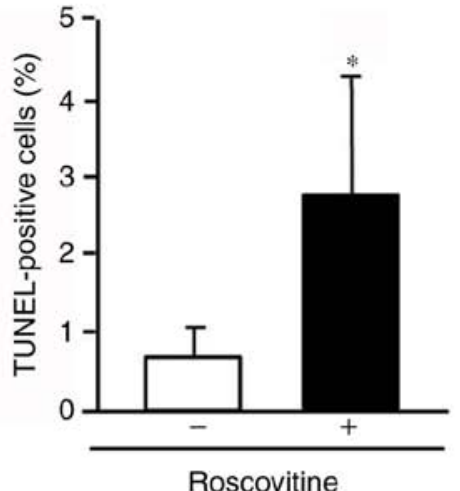

TFK-1

HUCCT-1

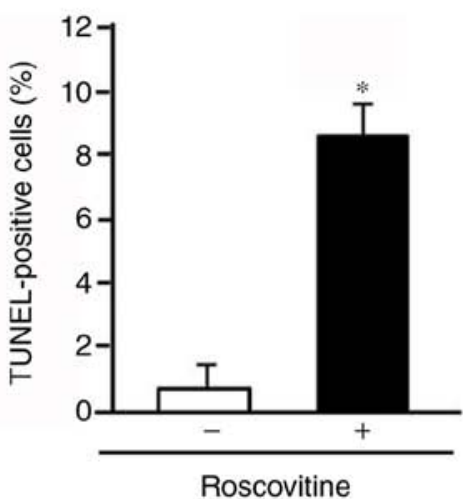

HUCCT-1

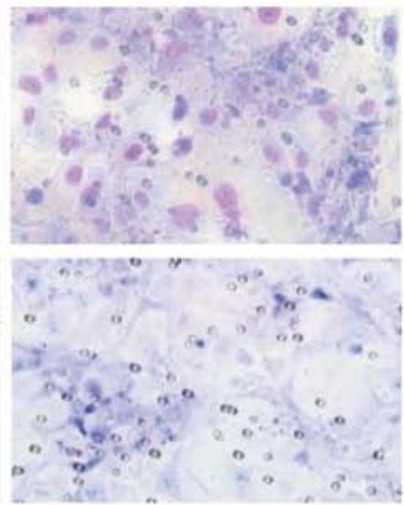

TFK-1

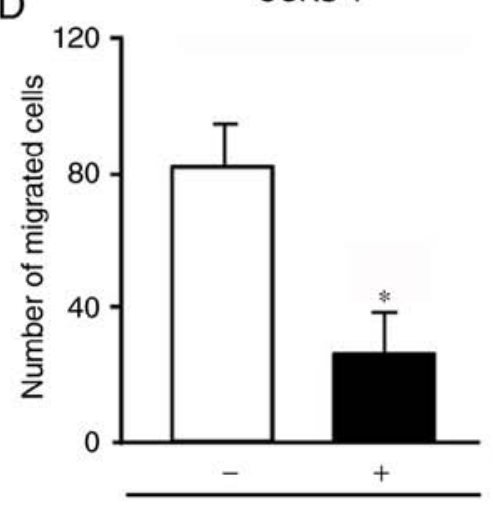

Roscovitine

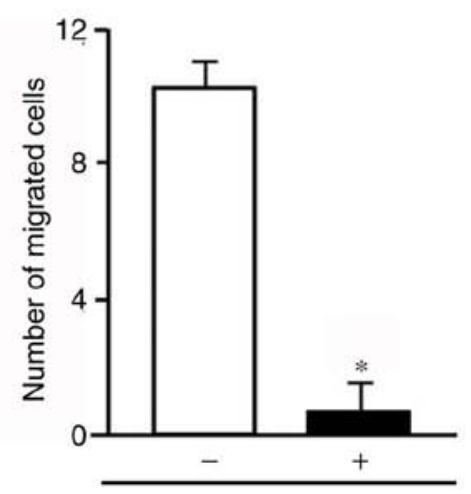

Roscovitine
HUCCT-1

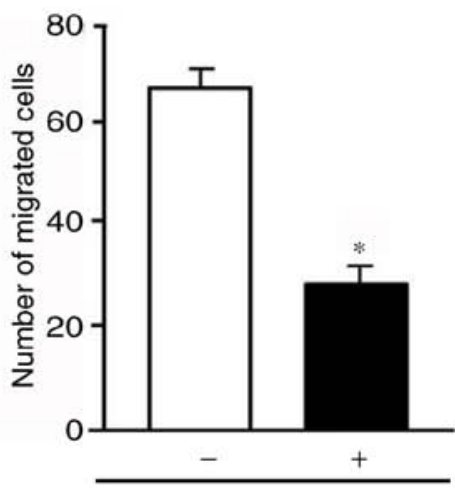

Roscovitine

Figure 5. Effects of roscovitine on apoptosis and cell invasion of cholangiocarcinoma in vitro. (A) Representative microphotographs of the TUNEL assay for the cholangiocarcinoma cell lines, CCKS-1, TFK-1, and HUCCT-1. Arrows indicate TUNEL-positive cells. (B) Induction of apoptosis in cells following roscovitine treatment. (C) Representative microphotographs of the invasion assay. (D) Inhibition of cell invasion following roscovitine treatment. Data were expressed as the mean \pm SD of five sets $(B$ and $D)$. The significance of differences was assessed using the Student's $t$-test. "P<0.05. Original magnification, $\mathrm{x} 1,000$ (A and C). TUNEL, terminal deoxynucleotide transferase-mediated dUTP nick end-labeling. 
A

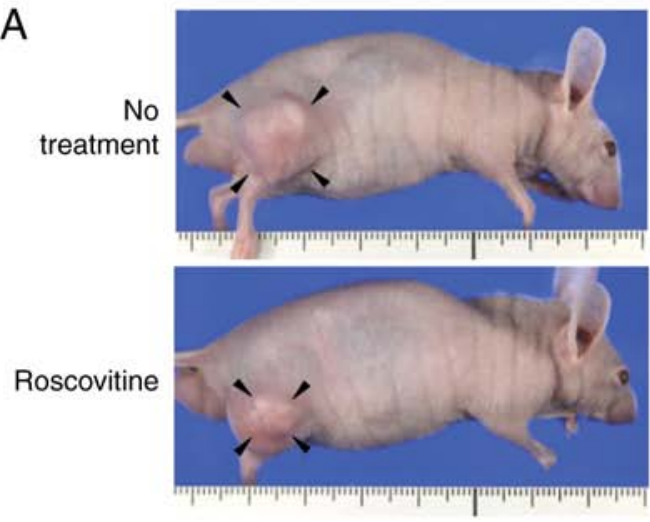

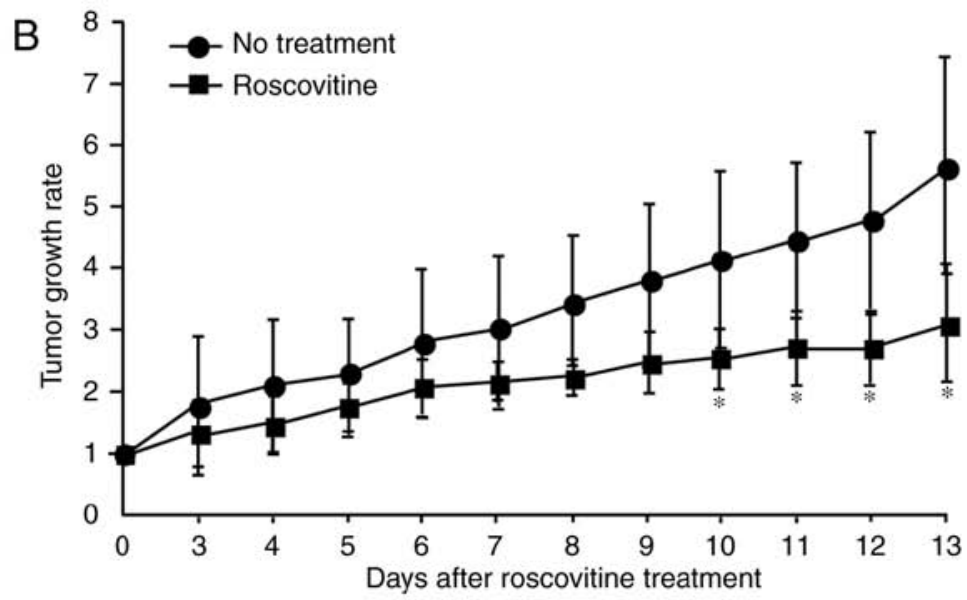

TUNEL

C
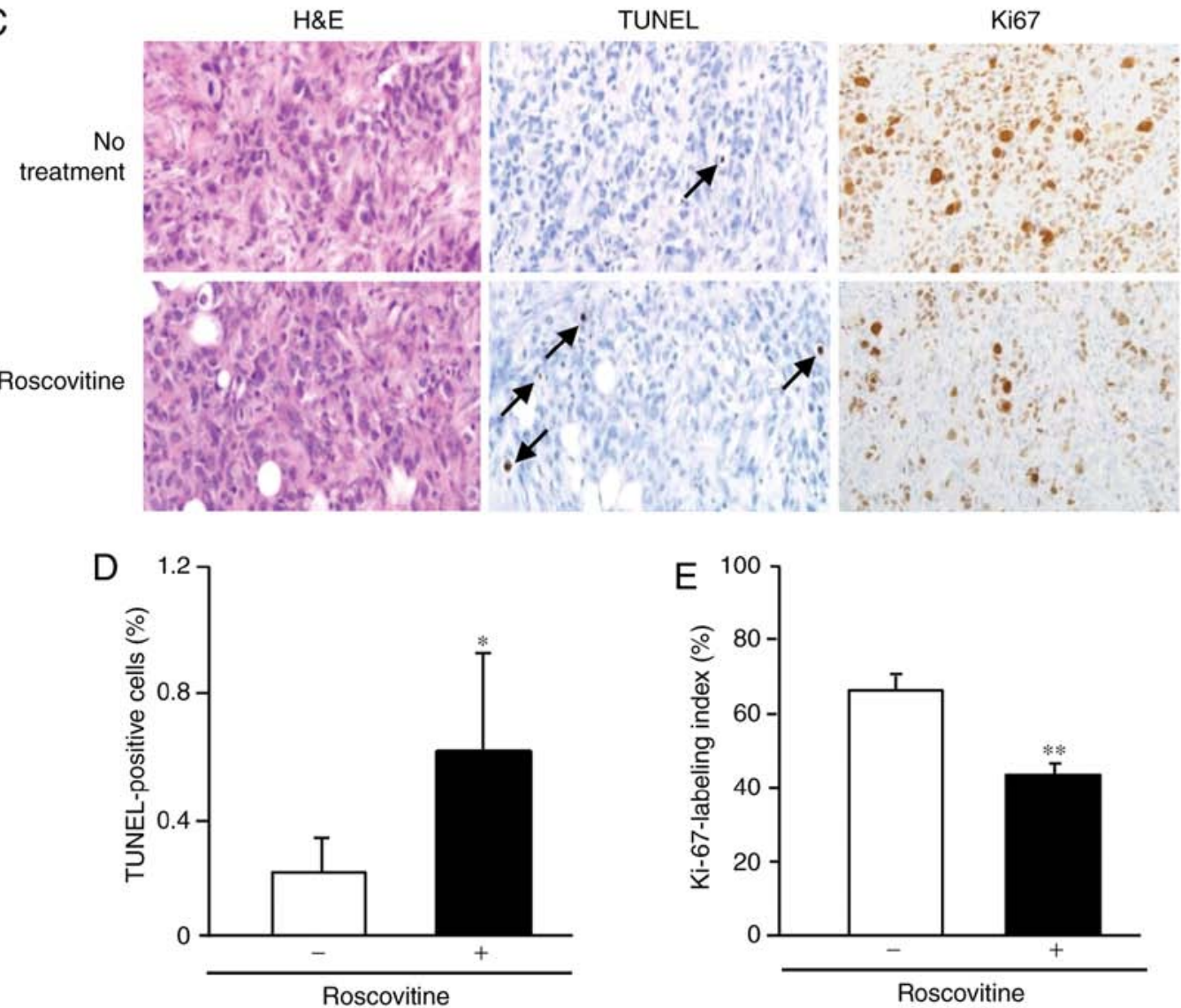

Figure 6. Effects of roscovitine on cholangiocarcinoma in a murine xenograft model. (A) Representative images of a murine xenograft model established by the subcutaneous implantation of the human cholangiocarcinoma cell line CCKS-1. Arrowheads indicate tumor nodules. (B) Time course of tumor growth in non-treated and roscovitine-treated mice. (C) Representative microphotographs of tumor tissues obtained from non-treated and roscovitine-treated mice. Arrows indicate TUNEL-positive cells. (D) Induction of apoptosis in cells following the roscovitine treatment. (E) Inhibition of cell proliferation following roscovitine treatment as assessed by the Ki-67-labeling index. Data were expressed as the mean $\pm \mathrm{SD}$ of five sets $(\mathrm{B}, \mathrm{D}$, and $\mathrm{E})$. The significance of differences was assessed using the Student's t-test. ${ }^{*} \mathrm{P}<0.05,{ }^{* *} \mathrm{P}<0.01$. Original magnifications, $\mathrm{x} 400$ (C). TUNEL, terminal deoxynucleotide transferase-mediated dUTP nick end-labeling.

unclear, and the effects of roscovitine on other CDKs may be involved. Therefore, studies using specific inhibitors of CDK1 are required to further clarify the biological significance of CDK1 in cholangiocarcinoma. Furthermore, the relationship between the KRAS mutation status and the extent of p-CDK1 expression needs to be analyzed in patients with cholangiocarcinoma.

In summary, the present study demonstrated that the pharmacological inhibition of CDK pathways using roscovitine reduced cell proliferation and the invasion of cholangiocarcinoma. These inhibitory effects were accompanied by cell cycle arrest at the G1 or G2/M phase and the induction of apoptosis. The immunohistochemical expression of p-CDK1 and cyclin B1 predicted the aggressive behavior of cholangiocarcinoma, and p-CDK1 may be a useful prognostic marker of cholangiocarcinoma. These results indicated that the CDK pathway involving CDK1 has potential as a therapeutic target for cholangiocarcinoma. 


\section{Acknowledgements}

Not applicable.

\section{Funding}

No funding was received.

\section{Availability of data and materials}

The datasets used and/or analyzed during the current study are available from the corresponding author on reasonable request.

\section{Authors' contributions}

MY performed the experiments and wrote the manuscript with technical support from KT. YS and KH conceived and designed the study. MS analyzed the data and provided comments. All authors participated in data interpretation and critically reviewed and approved the manuscript and agree to be accountable for all aspects of the work in ensuring that questions related to the accuracy or integrity of any part of the work are appropriately investigated and resolved.

\section{Ethics approval and consent to participate}

Experiments using human materials were performed with the approval of the Ethics Committee of Kanazawa University Graduate School of Medicine (Permit no. 1985-3). Protocols for animal studies were approved by the Committee of the Institute for Experimental Animals, Kanazawa University Advanced Science Research Center (Permit no. AP-173905).

\section{Patient consent for publication}

Not applicable.

\section{Competing interests}

The authors declare that they have no competing interests.

\section{References}

1. Razumilava N and Gores GJ: Cholangiocarcinoma. Lancet 383: 2168-2179, 2014

2. Rizvi S, Khan SA, Hallemeier CL, Kelley RK and Gores GJ: Cholangiocarcinoma-evolving concepts and therapeutic strategies. Nat Rev Clin Oncol 15: 95-111, 2018.

3. Cereda S, Passoni P, Reni M, Viganò MG, Aldrighetti L, Nicoletti R and Villa E: The cisplatin, epirubicin, 5-fluorouracil, gemcitabine (PEFG) regimen in advanced biliary tract adenocarcinoma. Cancer 116: 2208-2214, 2010.

4. Cheng W, Yang Z, Wang S, Li Y, Wei H, Tian X and Kan Q: Recent development of CDK inhibitors: An overview of CDK/inhibitor co-crystal structures. Eur J Med Chem 64: 615-639, 2019.

5. Schwartz GK and Shah MA: Targeting the cell cycle: A new approach to cancer therapy. J Clin Oncol 23: 9408-9421, 2005.

6. Deep G and Agarwal R: New combination therapies with cell cycle agents. Curr Opin Investig Drugs 9: 591-604, 2008.

7. Coxon CR, Anscombe E, Harnor SJ, Martin MP, Carbain B, Golding BT, Hardcastle IR, Harlow LK, Korolchuk S, Matheson CJ, et al: Cyclin-dependent kinase (CDK) inhibitors: Structure-activity relationships and insights into the CDK-2 selectivity of 6-substituted 2-arylaminopurines. J Med Chem 60 1746-1767, 2017.
8. Cai J, Li B, Zhu Y, Fang X, Zhu M, Wang M, Liu S, Jiang X, Zheng J, Zhang X, et al: Prognostic biomarker identification through integrating the gene signatures of hepatocellular carcinoma properties. EbioMedicine 19: 18-30, 2017.

9. Sung WW, Lin YM, Wu PR, Yen HH, Lai HW, Su TC, Huang RH, Wen CK, Chen CY, Chen CJ, et al: High nuclear/cytoplasmic ratio of Cdk1 expression predicts poor prognosis in colorectal cancer patients. BMC Cancer 14: 951, 2014.

10. Hongo F, Takaha N, Oishi M, Ueda T, Nakamura T, Naitoh Y, Naya Y, Kamoi K, Okihara K, Matsushima T, et al: CDK1 and CDK2 activity is a strong predictor of renal cell carcinoma recurrence. Urol Oncol 32: 1240-1246, 2014.

11. Shi YX, Zhu T, Zou T, Zhuo W, Chen YX, Huang MS, Zheng W, Wang CJ, Li X, Mao XY, et al: Prognostic and predictive values of CDK1 and MAD2L1 in lung adenocarcinoma. Oncotarget 7: 85235-85243, 2016.

12. Zhang C, Elkahloun AG, Robertson M, Gills JJ, Tsurutani J, Shih JH, Fukuoka J, Hollander MC, Harris CC, Travis WD, et al: Loss of cytoplasmic CDK1 predicts poor survival in human lung cancer and confers chemotherapeutic resistance. PLoS One 6: e23849, 2011.

13. García-Reyes B, Kretz AL Ruff JP, von Karstedt S, Hillenbrand A, Knippschild U, Henne-Bruns D and Lemke J: The emerging role of cyclin-dependent kinases (CDKs) in pancreatic ductal adenocarcinoma. Int J Mol Sci 19: pii: E3219, 2018.

14. Feldmann G, Mishra A, Bisht S, Karikari C, Garrido-Laguna I, Rasheed Z, Ottenhof NA, Dadon T, Alvarez H, Fendrich V, et al: Cyclin-dependent kinase inhibitor Dinaciclib (SCH727965) inhibits pancreatic cancer growth and progression in murine xenograft models. Cancer Biol Ther 12: 598-609, 2011.

15. Whittaker SR, Mallinger A, Workman P and Clarke PA: Inhibitors of cyclin-dependent kinases as cancer therapeutics. Pharmacol Ther 173: 83-105, 2017.

16. Costa-Cabral S, Brough R, Konde A, Aarts M, Campbell J, Marinari E, Riffell J, Bardelli A, Torrance C, Lord CJ, et al: CDK1 is a synthetic lethal target for KRAS mutant tumours. PLoS One 11: e0149099, 2016.

17. Churi CR, Shroff R, Wang Y, Rashid A, Kang HC, Weatherly J, Zuo M, Zinner R, Hong D, Meric-Bernstam F, et al: Mutation profiling in cholangiocarcinoma: Prognostic and therapeutic implications. PLoS One 9: e115383, 2014.

18. Nakamura H, Arai Y, Totoki Y, Shirota T, Elzawahry A, Kato M, Hama N, Hosoda F, Urushidate T, Ohashi S, et al: Genomic spectra of biliary tract cancer. Nat Genet 47: 1003-1010, 2015.

19. Mertens JC, Rizvi S and Gores GJ: Targeting cholangiocarcinoma. Biochim Biophys Acta Mol Basis Dis 1864: 1454-1460, 2018.

20. He W, Wang B, Zhuang Y, Shao D, Sun K and Chen J: Berberine inhibits growth and induces G1 arrest and apoptosis in human cholangiocarcinoma QBC939 cells. J Pharmacol Sci 119: 341-348, 2012.

21. Zheng J, Li Q, Wang W, Wang Y, Fu X, Wang W, Fan L and Yan W: Apoptosis-related protein-1 acts as a tumor suppressor in cholangiocarcinoma cells by inducing cell cycle arrest via downregulation of cyclin-dependent kinase subunits. Oncol Rep 35: 809-816, 2016

22. Samukawa E, Fujihara S, Oura K, Iwama H, Yamana Y, Tadokoro T, Chiyo T, Kobayashi K, Morishita A, Nakahara M, et al: Angiotensin receptor blocker telmisartan inhibits cell proliferation and tumor growth of cholangiocarcinoma through cell cycle arrest. Int J Oncol 51: 1674-1684, 2017.

23. Boueroy P, Aukkanimart R, Boonmars T, Sriraj P, Ratanasuwan P, Juasook A, Wonkchalee N, Vaeteewoottacharn K and Wongkham S: Inhibitory effect of aspirin on cholangiocarcinoma cells. Asian Pac J Cancer Prev 18: 3091-3096, 2017.

24. Sugawara H, Yasoshima M, Katayanagi K, Kono N, Watanabe Y, Harada K and Nakanuma Y: Relationship between interleukin-6 and proliferation and differentiation in cholangiocarcinoma. Histopathology 33: 145-153, 1998.

25. Tirado OM, Mateo-Lozano S and Notario V: Roscovitine is an effective inducer of apoptosis of Ewing's sarcoma family tumor cells in vitro and in vivo. Cancer Res 65: 9320-9327, 2005.

26. Brierley JD, Gospodarowics MK and Wittekind C: International union against cancer (UICC). TNM Classification of Malignant Tumors, 8th edition. New York, John Wiley and Sons, LTD., 2017.

27. Salaun P, Rannou Y and Prigent C: Cdk1, Plks, Auroras, and Neks: The mitotic bodyguards. Adv Exp Med Biol 617: 41-56, 2008. 
28. Gavet $\mathrm{O}$ and Pines J: Progressive activation of cyclinB1-Cdk1 coordinates entry to mitosis. Dev Cell 18: 533-543, 2010.

29. Gavet O and Pines J: Activation of cyclin B1-Cdk1 synchronizes events in the nucleus and the cytoplasm at mitosis. J Cel Biol 189: 247-259, 2010.

30. Keenan SM, Bellone C and Baldassare JJ: Cyclin-dependent kinase 2 nucleocytoplasmic translocation is regulated by extracellular regulated kinase. J Biol Chem 276: 22404-22409, 2001.

31. Won KA and Reed SI: Activation of cyclin E/CDK2 is coupled to site-specific autophosphorylation and ubiquitin-dependent degradation of cyclin E. EMBO J 15: 4182-4193, 1996.

32. Parry D, Guzi T, Shanahan F, Davis N, Prabhavalkar D, Wiswell D, Seghezzi W, Paruch K, Dwyer MP, Doll R, et al Dinaciclib (SCH 727965), a novel and potent cyclin-dependent kinase inhibitor. Mol Cancer Ther 9: 2344-2353, 2010.

33. Wei D, Parsels LA, Karnak D, Davis MA, Parsels JD, Marsh AC, Zhao L, Maybaum J, Lawrence TS, Sun Y, et al: Inhibition of protein phosphatase $2 \mathrm{~A}$ radiosensitizes pancreatic cancers by modulating $\mathrm{CDC} 25 \mathrm{C} / \mathrm{CDK} 1$ and homologous recombination repair. Clin Cancer Res 19: 4422-4432, 2013.

34. Nilubol N, Boufraqech M, Zhang L, Gaskins K, Shen M, Zhang YQ, Gara SK, Austin CP and Kebebew E: Synergistic combination of flavopiridol and carfilzomib targets commonly dysregulated pathways in adrenocortical carcinoma and has biomarkers of response. Oncotarget 9: 33030-33042, 2018.

35. Coley HM, Shotton CF and Thomas H: Seliciclib (CYC202; r-roscovitine) in combination with cytotoxic agents in human uterine sarcoma cell lines. Anticancer Res 27: 273-278, 2007.

36. Wesierska-Gadek J, Borza A, Komina O and Maurer M: Impact of roscovitine, a selective CDK inhibitor, on cancer cells: Bi-functionality increases its therapeutic potential. Acta Biochim Pol 56: 495-501, 2009.
37. Nair BC, Vallabhaneni S, Tekmal RR and Vadlamudi RK: Roscovitine confers tumor suppressive effect on therapy-resistant breast tumor cells. Breast Cancer Res 13: R80, 2011.

38. Cicenas J, Kalyan K, Sorokinas A, Stankunas E, Levy J, Meskinyte I, Stankevicius V, Kaupinis A and Valius M: Roscovitine in cancer and other diseases. Ann Transl Med 3: 135, 2015.

39. Bukanov NO, Moreno SE, Natoli TA, Rogers KA Smith LA, Ledbetter SR, Oumata N, Galons H, Meijer L and Ibraghimov-Beskrovnaya O: CDK inhibitors R-roscovitine and S-CR8 effectively block renal and hepatic cystogenesis in an orthologous model of ADPKD. Cell Cycle 11: 4040-4046, 2012.

40. Jin X, Yang C, Fan P, Xiao J, Zhang W, Zhan S, Liu T, Wang D and $\mathrm{Wu} \mathrm{H}$ : CDK5/FBW7-dependent ubiquitination and degradation of EZH2 inhibits pancreatic cancer cell migration and invasion. J Biol Chem 292: 6269-6280, 2017.

41. Appleyard MV, O'Neill MA, Murray KE, Paulin FE, Bray SE, Kernohan NM, Levison DA, Lane DP and Thompson AM: Seliciclib (CYC202, R-roscovitine) enhances the antitumor effect of doxorubicin in vivo in a breast cancer xenograft model. Int J Cancer 124: 465-472, 2009.

42. Saijyo S, Kudo T, Suzuki M, Katayose Y, Shinoda M, Muto T, Fukuhara K, Suzuki T and Matsuno S: Establishment of a new extrahepatic bile duct carcinoma cell line, TFK-1. Tohoku J Exp Med 177: 61-71, 1995

43. Yoshikawa D, Ojima H, Kokubu A, Ochiya T, Kasai S, Hirohashi S and Shibata T: Vandetanib (ZD6474), an inhibitor of VEGFR and EGFR signalling, as a novel molecular-targeted therapy against cholangiocarcinoma. Br J Cancer 100: 1257-1266, 2009. 